\title{
Uniform Versus Discriminatory Tariffs
}

\author{
Hassan Khodavaisi* Nigar Hashimzade ${ }^{\dagger} \quad$ Gareth D Myles ${ }^{\ddagger}$
}

September 2007

\begin{abstract}
We analyze the non-cooperative interaction between two foreign exporting countries producing differentiated products and one domestic importing country when governments use optimal policies to maximize welfare. The analysis extends the model of Liao and Wong (2006) to include product differentiation, asymmetric costs, and Bertrand competition. For identical exporting countries we demonstrate that the importing country always prefers a uniform tariff regime while the two exporting countries prefer a discriminatory tariff regime for any degree of product differentiation and for Bertrand competition. If countries are asymmetric in terms of production cost then the higher-cost exporter always prefers the discriminatory regime but the lower-cost exporter prefers the uniform regime if there is a significant cost differential. With the cost asymmetry the announcement of a uniform tariff regime by the importer is not a credible strategy since there is an incentive to deviate to discrimination. This implies an international body can play a role in ensuring that tariff agreements are respected.
\end{abstract}

Keywords: MFN Clause, product differentiation, Cournot competition, discriminatory tariffs.

JEL-Classification: F12, F13

\section{Introduction}

Imperfectly competitive markets cause a deviation from the efficient outcome and provide a pretext for government intervention. In the trade literature it is now well understood that a country can gain through unilateral intervention in an imperfectly competitive market (see Brander 1995, Brander and Spencer 1984, 1985). According to models of strategic trade policy with immobile but imperfectly competitive firms, there is a welfare gain for a country from shifting rents to the firms in its jurisdiction (by using a subsidy) or to the government (by using a tariff). When several countries simultaneously intervene the outcome can be mutually damaging. One response suggested in the literature to

\footnotetext{
*Corresponding author: H.Khodavaisi@Urmia.ac.ir

${ }^{\dagger}$ University of Exeter

$\ddagger$ University of Exeter and Institute for Fiscal Studies
} 
eliminate the unwelcome distortions caused by such unilateral trade policies is the adoption of free trade since all countries would be better off if none intervened. One step toward creating a free-trade environment is for supranational institutions like GATT/WTO to impose harmonized international rules on the nations involved in international trade.

An important example of such a rule is the Most Favored Nation (MFN) clause. The MFN clause is an important part of all multilateral trade agreements. Horn and Mavroidis (2001) and Hoekman and Kostecki (2001) describe MFN as one of the pillars of the WTO system. At the core of MFN is the idea of non-discrimination or symmetric treatment for all ${ }^{1}$. In other words, if country $A$ grants country $B$ the status of MFN, it simply agrees to treat country $B$ no worse than any other country. Thus, it is natural to ask whether a regime of MFN tariffs is better or worse than a regime of tariff discrimination.

Gatsios (1990) and Hwang and Mai (1991) investigated optimal discriminatory tariffs on two foreign firms located in two different countries. They demonstrated that an importing country prefers to impose discriminatory or preferential tariffs, rather than a uniform tariff across different countries, when the supplying firms have different production costs. This result is not surprising because the importing country has two instruments in the discriminatory tariff regime compared with just one instrument with the uniform tariff regime. A more interesting result is that the tariff on the low-cost firm should be higher than that on the high-cost firm. Therefore, with discriminatory tariffs, the total cost (marginal production cost plus specific tariff) differential between imports from different countries becomes smaller. In terms of production efficiency, production is diverted from the more efficient to the less efficient country under a discriminatory tariff regime. The consequences of enforcing a uniform tariff regime by imposing the MFN principle will be an overall gain in production efficiency with distributional effects favoring the cost-efficient country.

Gatsios (1990) and Hwang and Mai (1991) assumed that the exporting countries are not active in setting policy. Hence, it is important to ask whether the conclusions remain valid when both exporting governments also engage in trade policy. Liao and Wong (2006) allowed all three governments (the governments of the two exporting countries and that of the importing country) to be active in terms of choosing optimal policies that maximize their welfare. For symmetric exporting countries producing perfect substitute goods and engaging in Cournot competition, they found that the importing country would choose a uniform tariff regime, whereas the exporting countries would prefer a discriminatory tariff regime. This is an interesting result, but the assumptions of homogenous products and Cournot competition leave open the question of whether it is robust in a more general environment.

We extend the analysis of Liao and Wong (2006) in three different directions. First, we introduce product differentiation to move away from homoge-

\footnotetext{
${ }^{1}$ Although the GATT/WTO prohibits discriminatory import tariffs, the means for such policy exist within GATT/WTO rules. For example, discriminatory tariffs can be imposed through the enforcement of anti-dumping duty laws. Hence there are many ways by which the WTO/GATT's ban on discriminatory import tariffs can be and is circumvented.
} 
nous products. Second, we allow for countries that are asymmetric in terms of production costs. Third, we consider both Cournot and Bertrand competition. Using this generalized model we analyze the welfare consequences of two different tariff regimes: a uniform tariff regime, as required by the MFN clause of GATT/WTO, and a discriminatory tariff regime. We employ the model to address how export subsidies affect the tariff rates and tariff regime chosen by the importing country, whether exporting countries still pay a subsidy to their firms (as proposed by Brander and Spencer (1985), and others) when it is known that the importing country will respond, and whether countries achieve a mutually beneficial outcome by agreeing to constrain their choices through MFN. We also address the credibility of tariff regime announcements by the importing country.

Under a uniform tariff regime Liao and Wong (2006) prove, for goods that are perfect substitute, that both exporting countries subsidize the firm in their jurisdiction to shift rent from the importing country to its firm. We show that their result is robust if goods are nearly perfect substitutes but breaks down if the goods are sufficiently differentiated. Liao and Wong also show that for identical exporting countries the importing country always prefers a uniform tariff regime while the two exporting countries prefer a discriminatory tariff regime. We demonstrate this result holds for any degree of product differentiation and for Bertrand competition. If countries are asymmetric in terms of production costs the high-cost exporter always prefers the discriminatory regime, but the low-cost producer prefers the uniform regime if there is a significant cost differential.

We follow Liao and Wong (2006) by analyzing the consequences of the importing country announcing the tariff regime before level of the tariffs. However, we also consider whether such an announcement can be credible. If the two exporting countries are identical then the importer has no incentive to deviate from the announced tariff regime. With a cost asymmetry the announcement of a uniform tariff regime by the importer is not a credible strategy since there is an incentive to deviate to a discriminatory regime. The discriminatory tariffs chosen after deviation harm the low-cost exporter and reduce global welfare. These findings imply that an international body can play a role in ensuring tariff agreements are respected and provide motivation for the importing country to make an international commitment to follow an announced tariff regime (such as to follow the MFN clause of GATT/WTO) which cannot be easily changed.

The paper is structured as follows. In section 2 we describe the model used in the paper and derive the equilibrium for the discriminatory tariff regime and the uniform tariff regime under the assumption of Cournot competition. Section 3 provides a welfare comparison of the two tariff regimes. This is undertaken for symmetric exporters and then for asymmetric exporters. Section 4 analyzes the credibility of tariff regime announcements by the importing country. It is shown in Section 5 that the same qualitative results hold for Bertrand competition between the exporters. Section 6 concludes. 


\section{$2 \quad$ Model and Equilibrium}

The basic structure of the model is adopted from Hwang and Mai (1991) and Liao and Wong (2006). The world economy consists of three countries and two firms producing differentiated products. The domestic country imports the differentiated products from the foreign countries. For simplicity, we assume that the domestic country does not produce these products nor do the foreign countries consume them. It is also assumed that the domestic government understands the structure of the oligopolistic industry and is able to set credible tariffs on imports. Throughout the paper we consider only the case of a specific tariff. $^{2}$ The main differences between this paper and Liao and Wong (2006) are that they analyze Cournot competition with homogenous products while we focus upon differentiated products and also consider Bertrand competition. Hwang and Mai (1991) consider Cournot competition for differentiated products but with inactive exporting governments. In contrast, we allow the exporting countries to be active in the determination of policy.

\section{$2.1 \quad$ Structure}

The governments of the three countries choose their policy variables to maximize the welfare of their countries. The government of each exporting country chooses an export subsidy, while the government of the importing country chooses a tariff. To analyze the interactions among the governments we consider the following four-stage non-cooperative game. In the first stage, the domestic importing country announces whether it is using a uniform tariff regime or a discriminatory tariff regime. In the second stage, the two foreign exporting countries choose their export subsidies simultaneously and non-cooperatively to maximize their welfare. In the third stage, after observing the export subsidies, the domestic importing country imposes tariffs according to the tariff regime it announced in the first stage. The firms move simultaneously in the last stage of the game and each firm takes the tariff and subsidy rates, as well as the decision of the other firm, as given. All technology and demand information is known to all parties. In what follows, we determine the equilibrium of the game for the two tariff regimes. The regimes are then compared in terms of the welfare of the domestic importing country and the welfare of the foreign exporting countries.

The demand side of the model in the domestic country is derived from the utility maximization problem of a representative consumer. Label the two imported goods as 1 and 2 (the same labels are also adopted for the countries from which the goods originate) and denote the net benefit function of the domestic consumer by

$$
U=u\left(q_{1}, q_{2}\right)+Z
$$

where $Z$ is a competitive numeraire good, and $q_{i}$ is the consumption of good $i$.

\footnotetext{
${ }^{2}$ This is done for analytical simplicity. Note that in the competitive case, specific and ad valorem tariffs lead to the same outcomes, while under imperfect competition they lead to different outcomes.
} 
The sub-utility function is

$$
u\left(q_{1}, q_{2}\right)=q_{1}+q_{2}-\frac{1}{2}\left(q_{1}^{2}+2 \gamma q_{1} q_{2}+q_{2}^{2}\right), \quad 0 \leq \gamma \leq 1 .
$$

The parameter $\gamma$ indicates the extent of product differentiation (see Tirole, 1990). At $\gamma=1$ the products are perfect substitutes. As $\gamma$ decreases the products become less homogenous, and at $\gamma=0$ the demands for the two goods are independent. From the utility function it is straightforward to derive the inverse demand functions

$$
p_{1}=1-q_{1}-\gamma q_{2}, \quad p_{2}=1-q_{2}-\gamma q_{1} .
$$

Firm $i$ has constant marginal cost, $c_{i}$, and a fixed cost, $F_{i}$. Since we do not deal with the entry of firms, fixed costs are set to zero for simplicity. The level of profit, $\pi_{i}$, for firm $i$ is

$$
\pi_{i}=\left(p_{i}-c_{i}+s_{i}-t_{i}\right) q_{i},
$$

where $p_{i}$ is the price received, $s_{i}$ is the export subsidy imposed by country $i$, and $t_{i}$ is the import tariff imposed by the importing country on goods from country $i$. With Cournot competition, the equilibrium output of firm $i$ is

$$
q_{i}=\frac{2\left(1+s_{i}-c_{i}-t_{i}\right)-\gamma\left(1+s_{j}-c_{j}-t_{j}\right)}{4-\gamma^{2}} .
$$

With Bertrand competition, the equilibrium price charged by firm $i$ is

$$
p_{i}=\frac{2\left(1-s_{i}+c_{i}+t_{i}\right)-\gamma\left(1+\gamma+s_{j}-c_{j}-t_{j}\right)}{4-\gamma^{2}}
$$

It can be seen from (5) and (6) that with the functional forms used here the equilibrium prices and quantities may become negative for some combinations of costs. Since negative prices and quantities make no economic sense in this context, the analysis of later sections restricts attention to permissible cost combinations that ensure all values are nonnegative in equilibrium.

The importing country chooses the tariffs imposed to maximize consumer surplus

$$
W=u\left(q_{1}, q_{2}\right)-p_{1} q_{1}-p_{2} q_{2} .
$$

Under the discriminatory tariff regime it chooses (potentially) different tariff rates $t_{1}$ and $t_{2}$. Under the uniform tariff regime it sets the same tariff rate $t=t_{1}=t_{2}$ on the imports from both countries. The exporting countries choose their subsidy rates simultaneously to maximize their own firm's profit net of subsidies

$$
W_{i}=\pi_{i}-s_{i} q_{i} .
$$

In this section we consider Cournot competition between the two firms. The results for Bertrand competition are qualitatively identical to those for Cournot and are briefly described in Section 5. 


\subsection{Discriminatory tariff regime}

Assume that the importing country announces it will employ the differentiated tariff regime. After the announcement of the regime each exporting country chooses its export subsidy. The exporters move simultaneously, each taking the export subsidy of its competitor as given but being aware of how the choice of subsidy will subsequently affect the tariff. In the following stage, the importing country chooses the tariffs, taking the exporters' subsidies as given.

Solving the game shows that the equilibrium export subsidies are equal to

$$
s_{i}^{D}=-\frac{\left(3-\gamma^{2}\right)\left[\left(12-\gamma^{2}\right)\left(1-c_{i}\right)-3 \gamma\left(1-c_{j}\right)\right]}{\left(12-3 \gamma-\gamma^{2}\right)\left(12+3 \gamma-\gamma^{2}\right)} .
$$

The equilibrium tariffs set by the importing country are

$$
t_{i}^{D}=\frac{3\left[\left(12-\gamma^{2}\right)\left(1-c_{i}\right)-3 \gamma\left(1-c_{j}\right)\right]}{\left(12-3 \gamma-\gamma^{2}\right)\left(12+3 \gamma-\gamma^{2}\right)} .
$$

It can be seen from (9) and (10) that the equilibrium tariffs and subsidies have opposite signs for any degree of product differentiation and any production costs. The differences between the two subsidies and the two tariffs are

$$
\begin{aligned}
s_{1}^{D}-s_{2}^{D} & =\frac{\left(3-\gamma^{2}\right)\left(c_{1}-c_{2}\right)}{12-3 \gamma-\gamma^{2}} \\
t_{1}^{D}-t_{2}^{D} & =\frac{3\left(c_{2}-c_{1}\right)}{12-3 \gamma-\gamma^{2}} .
\end{aligned}
$$

Analysis of the differences in (11) and (12) shows that the high-cost country subsidizes its exports more heavily (or taxes its exports less) and faces a lower tariff than the low-cost country. The discriminatory tariff policy has the effect of partly equalizing the cost differences between the exporters and extracting relatively more of the surplus of the low-cost exporter.

When the welfare comparisons are made in the next section the case of equal production cost is particularly important. With equal production costs, $c_{1}=c_{2}=c$, the equilibrium tariffs and subsidies are given by

$$
\begin{aligned}
& t_{1}^{D}=t_{2}^{D}=\frac{3(1-c)}{12+3 \gamma-\gamma^{2}} \equiv t_{E}^{D}, \\
& s_{1}^{D}=s_{2}^{D}=-\frac{(3-\gamma)(1-c)}{12+3 \gamma-\gamma^{2}} \equiv s_{E}^{D} .
\end{aligned}
$$

It can be seen directly that the equilibrium tariff is positive and the equilibrium subsidy is negative. The negative subsidy implies that exports are taxed.

\subsection{Uniform tariff regime}

When the uniform tariff regime is in operation the importing country sets a single tariff for the products from both exporting countries. The exporting countries remain free to set subsidies independently. 
The equilibrium value of the uniform tariff is

$$
t^{U}=\frac{5\left(2-c_{1}-c_{2}\right)}{2\left(17+3 \gamma-2 \gamma^{2}\right)}
$$

The equilibrium subsidy set by exporting country $i$ is

$$
s_{i}^{U}=\frac{\left(1-\gamma-\gamma^{2}\right)\left[5(1+2 \gamma)\left(1-c_{j}\right)-\left(29-4 \gamma-4 \gamma^{2}\right)\left(1-c_{i}\right)\right]}{\left(12-7 \gamma-\gamma^{2}\right)\left(17+3 \gamma-2 \gamma^{2}\right)} .
$$

It can be seen that the equilibrium uniform tariff rate is always positive, whereas the signs of the export subsidies depend on the degree of product differentiation and the values of the production costs.

The first factor in the numerator of $s_{i}^{U}$ is positive when the degree of product differentiation is high, $0 \leq \gamma<\gamma^{*}=(\sqrt{5}-1) / 2 \approx 0.618$, and negative when the two products are close substitutes, $\gamma^{*}<\gamma \leq 1$. In Figure 1 the dependence on production costs of the sign of the optimal subsidies is illustrated for different values of $\gamma$. For $\gamma<\gamma^{*}$ (the magenta and blue lines in the figure) the export subsidy of country 1 is positive above the solid line, negative below, and zero along the line, whereas the export subsidy of country 2 is positive to the right of the dashed line, negative to the left, and zero along the line. For $\gamma>\gamma^{*}$ (the red lines in the figure) the converse is true. The black lines correspond to $\gamma=\gamma^{*}$.

The difference between the two subsidies is

$$
s_{1}^{U}-s_{2}^{U}=\frac{2\left(1-\gamma-\gamma^{2}\right)\left(c_{1}-c_{2}\right)}{12-7 \gamma-2 \gamma^{2}} .
$$

With a high degree of product differentiation $\left(0 \leq \gamma<\gamma^{*}\right)$ the higher-cost country subsidizes its exports more heavily, or taxes them less, than the lower-cost country. With a low degree of product differentiation the situation is reversed.

With identical production costs, $c_{1}=c_{2}=c$, the tariff and subsidies become

$$
\begin{aligned}
t^{U} & =\frac{5(1-c)}{17+3 \gamma-2 \gamma^{2}} \equiv t_{E}^{U}, \\
s_{1}^{U} & =s_{2}^{U}=-\frac{2(1-c)\left(1-\gamma-\gamma^{2}\right)}{17+3 \gamma-2 \gamma^{2}} \equiv s_{E}^{U} .
\end{aligned}
$$

Note that these values are different from the case with identical costs under the discriminatory tariff regime. This difference is due to the change in strategic structure between the two regimes.

When the discriminatory tariff regime is in operation a country's choice of export subsidy affects the tariff on its product relative to the tariff on the other exporter's product. The tariff policy of the importer always operates to partly equalize cost differences, so it benefits the high-cost exporter relative to the low-cost exporter. This gives an incentive for each exporter to appear high cost. They achieve this by imposing a smaller subsidy (or even a tax) on exports. In contrast, when the uniform tariff regime is in operation there is no 


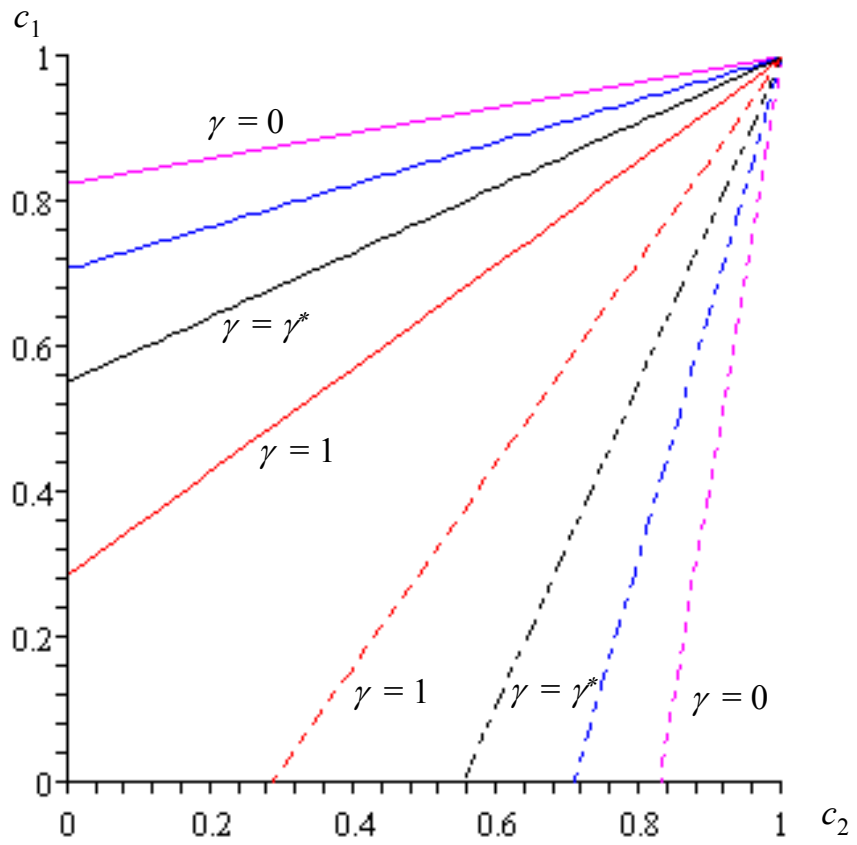

Figure 1: Signs of optimal subsidies 
relative advantage to be secured by manipulating the subsidy: any change in the uniform tariff also benefits the other exporting country. As a consequence, the equilibrium subsidies in the discriminatory regime are smaller that the subsidies in the uniform regime and this effect is stronger the closer substitutes are the two goods.

\section{Welfare comparison}

In this section we compare the welfare levels of the three countries under the two tariff regimes. This is first undertaken for the case of identical production costs and then for the case of asymmetric costs. The intention is to determine the preferences of the countries over the alternative regimes.

\subsection{Identical production costs}

As we have already observed the equilibrium tariffs and subsidies differ between the two regimes even when production costs are identical. These differences imply that the two regimes have different welfare consequences.

The assumption of identical production costs make the comparison of welfare levels between regimes straightforward. Direct computation determines that the welfare levels of the importer and the two exporters under the uniform regime with identical costs are

$$
\begin{aligned}
W_{I}^{U} & =\frac{25(1-c)^{2}(3+\gamma)}{\left(17+3 \gamma-2 \gamma^{2}\right)^{2}} \\
W_{E}^{U} & =\frac{5(1-c)^{2}\left(7-2 \gamma-2 \gamma^{2}\right)}{\left(17+3 \gamma-2 \gamma^{2}\right)^{2}}
\end{aligned}
$$

Under the discriminatory regime the corresponding welfare levels are

$$
\begin{aligned}
W_{I}^{D} & =\frac{9(1-c)^{2}(3+\gamma)}{\left(12+3 \gamma-\gamma^{2}\right)^{2}} \\
W_{E}^{D} & =\frac{3(1-c)^{2}\left(6-\gamma^{2}\right)}{\left(12+3 \gamma-\gamma^{2}\right)^{2}}
\end{aligned}
$$

The first proposition shows that the result of Liao and Wong (2006) concerning preferences over regimes extends to the setting of differentiated products.

Proposition 1 With identical production costs and any degree of product differentiation:

(i) The welfare level of the importing country is higher under the uniform tariff regime.

(ii) The welfare levels of the exporting countries are higher under the discriminatory tariff regime. 
Proof. The proposition can be proved by considering the welfare differences

$$
\begin{aligned}
W_{I}^{D}-W_{I}^{U} & =-\frac{(1-c)^{2}(3+\gamma)^{3}\left(111+24 \gamma-11 \gamma^{2}\right)}{\left(12+3 \gamma-\gamma^{2}\right)^{2}\left(17+3 \gamma-2 \gamma^{2}\right)^{2}}<0 \\
W_{E}^{D}-W_{E}^{U} & =\frac{2(1-c)^{2}(3+\gamma)^{3}\left(3+11 \gamma+2 \gamma^{2}-\gamma^{3}\right)}{\left(12+3 \gamma-\gamma^{2}\right)^{2}\left(17+3 \gamma-2 \gamma^{2}\right)^{2}}>0 .
\end{aligned}
$$

The proposition establishes that importing and exporting countries have different rankings of the two regimes. It may seem surprising that the importer prefers to have only one policy instrument when it is possible to have two. The explanation for this is that the exporters have a first-mover advantage and are able to manipulate the discriminatory regime to their advantage by reducing their subsidies. This point was emphasized when the equilibrium values of the tariffs and subsidies were contrasted. By announcing the uniform regime it is possible for the importer to reduce the incentive for the exporters to engage in this manipulation.

The fact that the preferences of the countries are not aligned makes it interesting to ask which regime maximizes the aggregate level of welfare. This question is answered by the next proposition which defines global welfare as the sum of the welfare levels of the importing country and two exporting countries.

Proposition 2 Global welfare is higher under the uniform tariff regime.

Proof. Summing the welfare levels in the two regimes and considering the difference gives

$$
\begin{aligned}
& \left(W_{I}^{D}+2 W_{E}^{D}\right)-\left(W_{I}^{U}+2 W_{E}^{U}\right) \\
= & -\frac{(1-c)^{2}(3+\gamma)^{3}\left(99-20 \gamma-19 \gamma^{2}+4 \gamma^{3}\right)}{\left(12+3 \gamma-\gamma^{2}\right)^{2}\left(17+3 \gamma-2 \gamma^{2}\right)^{2}}<0 .
\end{aligned}
$$

\subsection{Asymmetric production costs}

The consideration of asymmetric production costs for the two firms allows for a wider range of outcomes. In what follows we assume, for simplicity, that $c_{1}=0$ and $c_{2}=c$.

In the equilibrium under the discriminatory regime the subsidy levels chosen by the low-cost and the high-cost exporters, respectively, are

$$
s_{1}=-\frac{\left(3-\gamma^{2}\right)\left[12-3 \gamma(1-c)-\gamma^{2}\right]}{\left(12+3 \gamma-\gamma^{2}\right)\left(12-3 \gamma-\gamma^{2}\right)},
$$

and

$$
s_{2}=-\frac{\left(3-\gamma^{2}\right)\left[\left(12-\gamma^{2}\right)(1-c)-3 \gamma\right]}{\left(12+3 \gamma-\gamma^{2}\right)\left(12-3 \gamma-\gamma^{2}\right)} .
$$


Both the low-cost exporter and the high-cost exporter tax their exports for any $c$ and $\gamma$. The tariff levels chosen by the importing country are

$$
t_{1}=\frac{3\left[12-3 \gamma(1-c)-\gamma^{2}\right]}{\left(12+3 \gamma-\gamma^{2}\right)\left(12-3 \gamma-\gamma^{2}\right)},
$$

and

$$
t_{2}=\frac{3\left[\left(12-\gamma^{2}\right)(1-c)-3 \gamma\right]}{\left(12+3 \gamma-\gamma^{2}\right)\left(12-3 \gamma-\gamma^{2}\right)} .
$$

Under the uniform regime the subsidies and the tariff are

$$
\begin{aligned}
& s_{1}=-\frac{\left(1-\gamma-\gamma^{2}\right)[24+5 c(1+2 \gamma)-2 \gamma(7+2 \gamma)]}{\left(12-7 \gamma-2 \gamma^{2}\right)\left(17+3 \gamma-2 \gamma^{2}\right)}, \\
& s_{2}=-\frac{\left(1-\gamma-\gamma^{2}\right)\left[24-c\left(29-4 \gamma-4 \gamma^{2}\right)-2 \gamma(7+2 \gamma)\right]}{\left(12-7 \gamma-2 \gamma^{2}\right)\left(17+3 \gamma-2 \gamma^{2}\right)}
\end{aligned}
$$

and

$$
t=\frac{5(2-c)}{2\left(17+3 \gamma-2 \gamma^{2}\right)} .
$$

The low-cost exporter taxes its exports for $\gamma \leq \gamma^{*}=(\sqrt{5}-1) / 2$ and subsidizes its exports for $\gamma>\gamma^{*}$ for all values of $c$. For the high-cost exporter the result is more complicated: when the cost differential is low, the high-cost exporter taxes its exports for low values of $\gamma$ and subsidizes its exports for high values of $\gamma$. When the cost differential is high, the situation is reversed.

With $c_{1}=0$ and $c_{2}=c$ it is necessary to ensure that $q_{2}$ remains non-negative as $c$ increases. This places a limit on the range of costs that are consistent with each value of $\gamma$. Outside this range the high-cost country exports no output, so the distinction between regimes has little interest. The restrictions implied by the requirement for quantities to the positive are now investigated. Since the high-cost exporter always exports less only their output level needs to be considered.

In the equilibrium under the discriminatory regime the output level of the high-cost exporter is

$$
q_{2}=\frac{3\left[\left(12-\gamma^{2}\right)(1-c)-3 \gamma\right]}{\left(12+3 \gamma-\gamma^{2}\right)\left(12-3 \gamma-\gamma^{2}\right)} \geq 0 .
$$

The level of output is therefore positive if

$$
c \leq 1-\frac{3 \gamma}{12-\gamma^{2}} \equiv \bar{c}^{D}(\gamma) .
$$

Under the uniform tariff regime the equilibrium output of the high-cost exporter is

$$
q_{2}=\frac{5\left[\left(29-4 \gamma-4 \gamma^{2}\right)(1-c)-5(1+2 \gamma)\right]}{2\left(12-7 \gamma-2 \gamma^{2}\right)\left(17+3 \gamma-2 \gamma^{2}\right)} \geq 0,
$$


so that output is positive in this regime if

$$
c \leq 1-\frac{5(1+2 \gamma)}{29-4 \gamma-4 \gamma^{2}} \equiv \bar{c}^{U}(\gamma)
$$

From (32) and (34) it follows that

$$
\bar{c}^{U}(\gamma)-\bar{c}^{D}(\gamma)=-\frac{60+33 \gamma+7 \gamma^{2}+2 \gamma^{3}}{\left(12-\gamma^{2}\right)\left(29-4 \gamma-4 \gamma^{2}\right)}<0
$$

for all values of $\gamma$. Therefore, the constraint given by $\bar{c}^{U}(\gamma)$ binds first. This implies that to make a valid welfare comparison with both countries exporting we need to restrict $c$ to the interval $\left[0, \bar{c}^{U}(\gamma)\right]$ for every $\gamma$.

The welfare effects are summarized in the following proposition assuming $0 \leq c \leq \bar{c}^{U}(\gamma)$

Proposition 3 In an economy with asymmetric costs:

(i) The importer prefers the uniform regime for all $\gamma$.

(ii) There is a function $c_{1}(\gamma)$, which is increasing in $\gamma$ for $\gamma<\gamma_{1}$ and decreasing in $\gamma$ for $\gamma>\gamma_{1}$, such that the low-cost exporter prefers the discriminatory regime if $c<c_{1}(\gamma)$ and prefers the uniform regime otherwise.

(iii) The high-cost exporter prefers the discriminatory regime for all $c<$ $\bar{c}^{U}(\gamma)$, for all $\gamma$.

Proof. (Sketch) $)^{3}$ To prove part $(i)$ we write the importer's welfare difference as

$$
\Delta W_{I}=W_{I}^{D}-W_{I}^{U}=A_{1}(\gamma) c^{2}+A_{2}(\gamma) c+A_{3}(\gamma)
$$

and note that $A_{1}(\gamma)<0, A_{2}(\gamma)>0$, and $A_{3}(\gamma)<0$ for all $\gamma$. Therefore, at $c=0, \Delta W_{I}$ is negative and starts increasing as $c$ increases. The argument is completed by showing that $\Delta W_{I}=0$ at some $c>\bar{c}^{U}(\gamma)$ for any given $\gamma$.

Similarly, to prove part (iii) we show that

$$
\Delta W_{2 E}=W_{2 E}^{D}-W_{2 E}^{U}=B_{1}(\gamma) c^{2}+B_{2}(\gamma) c+B_{3}(\gamma)
$$

with $B_{1}(\gamma)<0, B_{2}(\gamma)>0$, and $B_{3}(\gamma)>0$ for all $\gamma$. Therefore, at $c=0, \Delta W_{2 E}$ is positive and increasing as $c$ increases. Also, the positive root of $\Delta W_{2 E}$ exceeds $\bar{c}^{U}(\gamma)$ for any given $\gamma$, and hence $\Delta W_{2 E}>0$ for all $\gamma$ as long as $c<\bar{c}^{U}(\gamma)$.

Finally, to prove part $(i i)$ we show that

$$
\Delta W_{1 E}=W_{1 E}^{D}-W_{1 E}^{U}=D_{1}(\gamma) c^{2}+D_{2}(\gamma) c+D_{3}(\gamma)
$$

where $D_{1}(\gamma)<0, D_{2}(\gamma)<0$, and $D_{3}(\gamma)>0$ for all $\gamma$. Therefore, at $c=0$, $\Delta W_{1 E}$ is positive and decreasing as $c$ increases. Also, the positive root of $\Delta W_{2 E}$ is less than $\bar{c}^{U}(\gamma)$ for all $\gamma$, and hence for every $\gamma$ the welfare difference $\Delta W_{2 E}$ switches sign at some $c(\gamma)<\bar{c}^{U}(\gamma)$.

\footnotetext{
${ }^{3}$ The detailed derivations are avaialbe from the authors on request.
} 


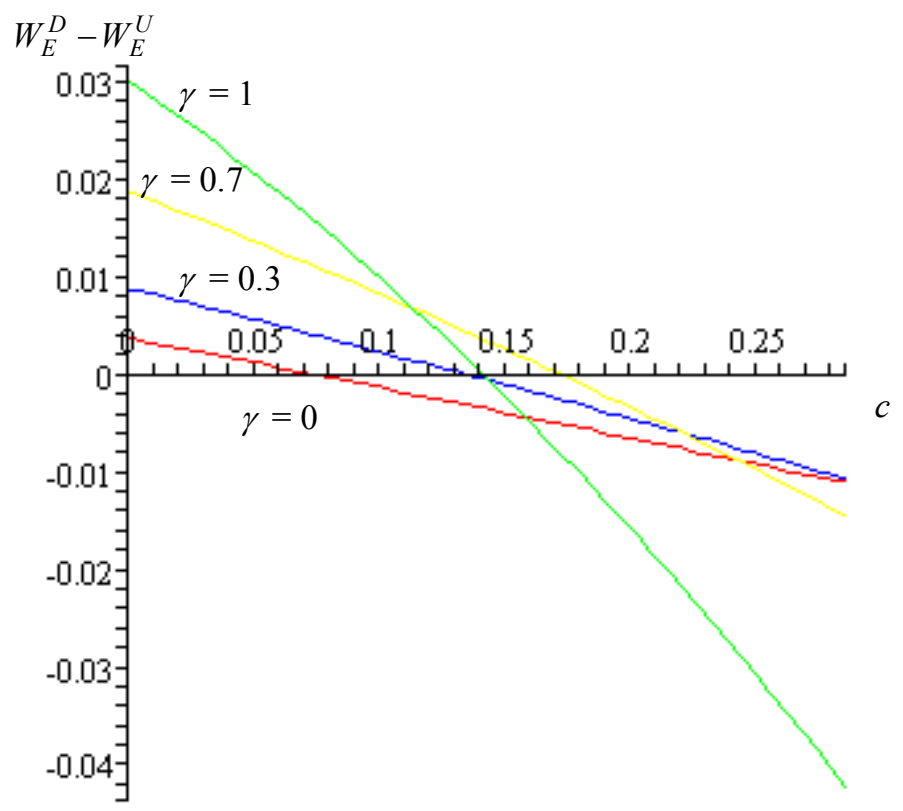

Figure 2: $W_{E}^{D}-W_{E}^{U}$ for the low-cost country in an asymmetric economy

This proposition demonstrates that the importer has a preference for uniform regime for all permissible values of $c$ and $\gamma$. This extends the result for identical costs. Conversely, the high-cost exporter is always better off under the discriminatory regime. The preferences of the low-cost exporter are more complex. The basis of the argument in (ii) of the proposition is illustrated in Figure 2. This country is only better off under the discriminatory tariff regime for small values of the cost differential. Otherwise it is better off under the uniform regime. For any $\gamma$ the switch of preference to the uniform regime occurs at a value of $c$ below $\bar{c}^{U}(1)=\frac{2}{7}$, which is the lowest permissible upper bound. As $\gamma$ increases the critical value of the cost differential rises until $\gamma=\tilde{\gamma}$ (see Figure 3 ), and then falls as $\gamma$ increases further.

The implications of the proposition for agreement over a regime are summarized in Figure 3. The low-cost exporter prefers the uniform regime above the blue curve; the high-cost exporter prefers the discriminatory regime below the green curve; and the importer prefers the uniform regime below the red curve. The yellow line represents $\bar{c}^{U}$, so that permissible values of $c$ and $\gamma$ lie below this curve. Therefore, between the yellow and blue curves the high-cost exporter prefers the discriminatory regime while the low-cost exporter and the import- 


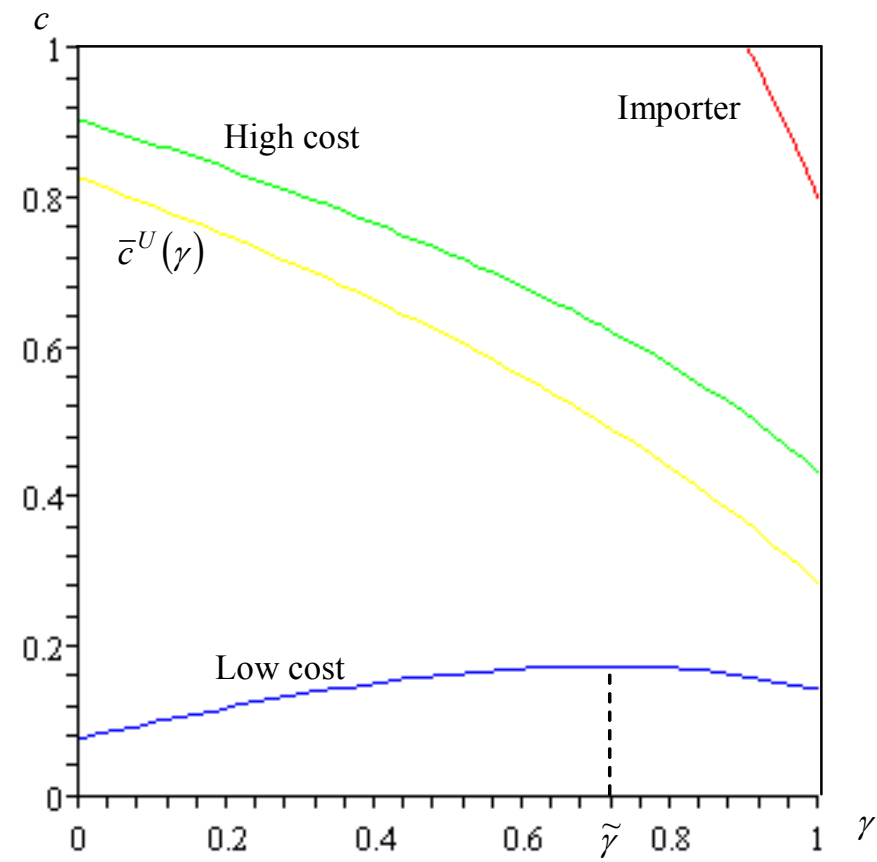

Figure 3: Preferences with Cournot competition

ing country prefer the uniform regime. Below the blue curve the two exporters prefer the discriminatory regime and the importer prefers the uniform regime. Consequently, within the permissible set there are no points for which all three countries are in agreement about the preferred regime.

The existing literature has established the preference of the importer for the uniform regime and the preference of the exporters for the discriminatory regime for the case of homogeneous products and identical costs. This is a special case of our model. Given equal costs the extension to differentiated products does not affect the conclusion. However, asymmetric costs do make a difference. For any given degree of differentiation the preferences over regimes will change as the cost asymmetry increases (consider moving vertically upwards from the horizontal axis in Figure 3). What is true for every set of permissible parameter values is a fundamental disagreement over the choice of regime: at no point do all three countries prefer the same regime. For all parameter values the importer will prefer to announce the uniform regime. This leads into the question of credibility that is addressed in the next section. Will the importer honor the announcement of a uniform regime after the exporters have set their subsidies?

As a prelude to considering credibility it is worth determining the level of 
world welfare for the two regimes. The difference in global welfare between two regimes for the asymmetric case can be written as

$$
\left(W_{I}^{D}+W_{1 E}^{D}+W_{2 E}^{D}\right)-\left(W_{I}^{U}+W_{1 E}^{U}+W_{2 E}^{U}\right)=F_{1}(\gamma) c^{2}+F_{2}(\gamma) c+F_{3}(\gamma),
$$

where $F_{1}(\gamma)<0$ and $F_{2}(\gamma)^{2}-4 F_{1}(\gamma) F_{3}(\gamma)<0$ for all $\gamma$. Therefore, the welfare difference is negative for all values of $c$ and $\gamma$. In the asymmetric world global welfare is always higher under the uniform tariff regime.

\section{Credibility of the announced policy}

We showed in the previous section that (i) in a symmetric world the importing country is better off under the uniform tariff regime while the exporting countries are better off under the discriminatory regime, and that (ii) in an asymmetric world there exists a set of values of $c$ and $\gamma$ for which two of the three countries are better off under the uniform regime. In neither case is it possible to have all three countries in agreement about the choice of regime. In this section we show that having announced the uniform tariff regime the importing country has an incentive to deviate to the discriminatory regime after the exporters choose their subsidy levels.

It is not surprising that there is an incentive to deviate. The uniform regime can be viewed as discriminatory with an additional constraint: under the discriminatory regime the importing country has two policy instruments, whereas under the uniform regime it has only one. In the game described to this point the exporters have first-mover advantage in setting subsidies and use this to negate the benefit to the importer of an additional policy tools in the discriminatory regime compared to the uniform regime. If the importer deviates to the discriminatory regime after the exporters have set their subsidies this overcomes the first-mover advantage and allows the increased number of policy tools to be exploited.

This argument is illustrated schematically in Figure 4. The subsidy level is on the horizontal axis, and the welfare of the importing country is on the vertical axis. For any given subsidy level chosen by the exporters the importer's welfare is higher under the discriminatory regime. However, the optimal choice of subsidies is lower under the discriminatory regime. Hence, the importer's welfare under the uniform regime, given the optimal choice of subsidy under the uniform regime, may be higher than importer's welfare under the discriminatory regime, given the optimal choice of subsidy under the discriminatory regime.

The central result concerning the credibility of the announcement of a uniform regime are summarized in the next proposition.

Proposition 4 (i) If production costs are identical then the announcement of the uniform regime is credible.

(ii) If production costs are asymmetric then the announcement of the uniform regime by the importer is not credible. 


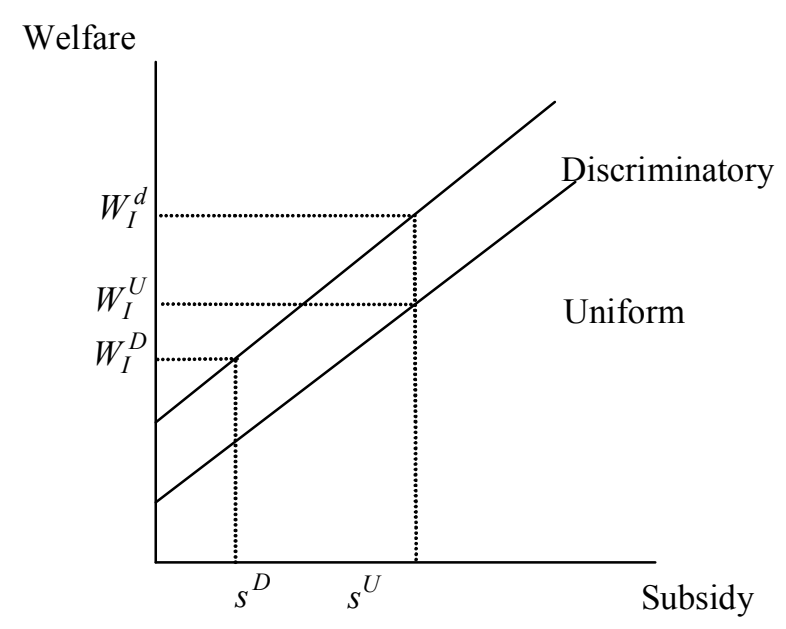

Figure 4: Gain from deviation

Proof. If the importer deviates to discriminatory tariffs after the exporters have chosen their subsidy levels its optimal choice of the tariffs is

$$
t_{i}^{d}=\frac{5\left(1-c_{i}\right)}{17+3 \gamma-2 \gamma^{2}}-\frac{\left(c_{i}-c_{j}\right)\left(4 \gamma^{2}+11 \gamma-1\right)}{(3-\gamma)\left(12-7 \gamma-2 \gamma^{2}\right)\left(17+3 \gamma-2 \gamma^{2}\right)}
$$

Using these tariff values the welfare gain of the importer is

$$
W_{I}^{d}-W_{I}^{U}=\frac{25\left(c_{i}-c_{j}\right)^{2}}{4(3-\gamma)\left(12-7 \gamma-2 \gamma^{2}\right)^{2}} .
$$

In the symmetric case the tariffs after deviation are the same as without deviation

$$
t_{1}^{d}=t_{2}^{d}=\frac{5(1-c)}{17+3 \gamma-2 \gamma^{2}},
$$

so therefore $W_{I}^{d}-W_{I}^{U}=0$, and the importing country's welfare is unchanged. If costs are asymmetric then $W_{I}^{d}-W_{I}^{U}>0$ and the importer gains from deviating to discrimination.

Hence, as long as the production costs are asymmetric the importer has an incentive to deviate to the discriminatory regime. The larger the difference in costs between the two exporting countries, the more the importing country benefits from such a deviation.

As a result of this deviation in the asymmetric case the low-cost exporter loses and the high-cost exporter gains since

$$
W_{1 E}^{d}-W_{1 E}^{U}=-A c^{2}-D c<0,
$$


and

$$
W_{2 E}^{d}-W_{2 E}^{U}=-B c^{2}+D c>0,
$$

where

$$
\begin{aligned}
A & =\frac{5\left(95+255 \gamma-190 \gamma^{2}-30 \gamma^{3}+20 \gamma^{4}\right)}{4\left(12-7 \gamma-2 \gamma^{2}\right)^{2}\left(17+3 \gamma-2 \gamma^{2}\right)(3-\gamma)^{2}}>0, \\
B & =\frac{5\left(959-681 \gamma-178 \gamma^{2}+146 \gamma^{3}+8 \gamma^{4}-8 \gamma^{5}\right)}{4\left(12-7 \gamma-2 \gamma^{2}\right)^{2}\left(17+3 \gamma-2 \gamma^{2}\right)(3-\gamma)^{2}}>0, \\
D & =\frac{5(3+\gamma)(2-\gamma)}{\left(12-7 \gamma-2 \gamma^{2}\right)\left(17+3 \gamma-2 \gamma^{2}\right)(3-\gamma)}>0 .
\end{aligned}
$$

Note that the low-cost exporter loses from the deviation even though they may prefer the discriminatory regime in some circumstances. This finding is a consequence of the partial equalization brought about by the discriminatory tariffs. Finally, deviation reduces global welfare

$$
\begin{aligned}
& W_{I, d}^{C}+W_{1 E, d}^{C}+W_{2 E, d}^{C}-\left(W_{I, U E}^{C}-W_{1 E, U E}^{C}-W_{2 E, U E}^{C}\right) \\
= & -\frac{5 c^{2}\left(47-31 \gamma-8 \gamma^{2}+4 \gamma^{3}\right)}{4(3-\gamma)^{2}\left(12-7 \gamma-2 \gamma^{2}\right)^{2}}<0 .
\end{aligned}
$$

These results demonstrate that the best strategy for the importer is to announce a uniform regime, allow the exporters to set subsidies on the basis of this announcement, and then to deviate to discrimination. This discrimination transfers surplus from the exporters to the importer. It also reduces the welfare of the low-cost exporter. This finding could be a reason why international bodies are required to sustain rules on tariff behavior. Since the outcome after deviation by the importer hurts the low-cost exporter it is in the interest of aiding efficient exporters to ensure that such opportunistic behavior of importers does not occur. This provides the justification for the MFN clause since it prevents deviation to discrimination. Observe that the low-cost exporter actually prefers discrimination if the cost differential is large, provided that it is announced in advance of the subsidy choice. It is deviation after announcement that is not liked.

\section{Bertrand competition}

Under Bertrand competition between the firms from the two exporting countries the outcome is qualitatively identical to the one under Cournot competition. We therefore provide only a brief summary of the conclusions.

The countries' preferences for regime are shown in Figure 5. The low-cost exporter prefers the uniform regime above the blue curve; the high-cost exporter prefers the discriminatory regime below the green curve; and the importer prefers the uniform regime below the red curve. The yellow line represents $\bar{c}^{U}$, so that permissible values of $c$ and $\gamma$ lie below this curve. Therefore, between 


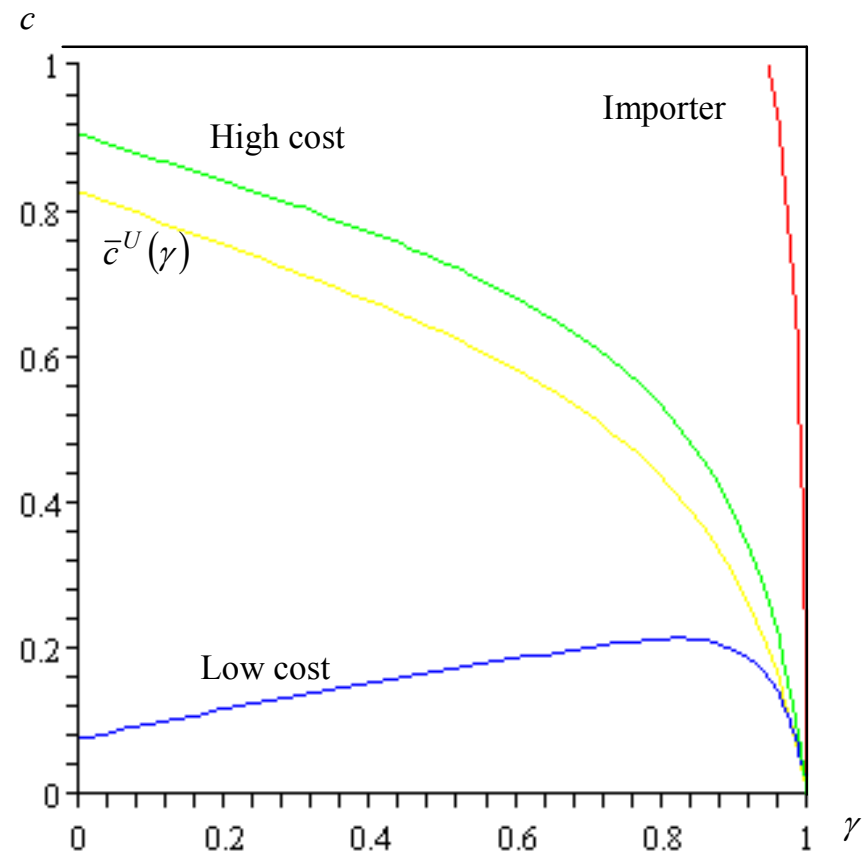

Figure 5: Preferences with Bertrand competition

the yellow and green curves the high-cost exporter prefers the discriminatory regime while the low-cost exporter and the importing country prefer the uniform regime. Below the blue curve the two exporters prefer the discriminatory regime and the importer prefers the uniform regime. Consequently, within the permissible set there are no points for which all three countries are in agreement about the preferred regime.

It remains true that the importing country has an incentive to deviate to the discriminatory regime after announcing the uniform tariff regime. As a result of such deviation, the low-cost exporter incurs a welfare loss, the highcost exporter gains, and the global welfare is reduced. These results are all exactly as for Cournot competition. Thus, changing the mode of competition does not change any of the conclusions.

\section{Summary}

The paper has addressed the question of whether countries can achieve a mutually beneficial outcome by following the MFN principle, i.e. the importing country applies the same tariff to all exporting countries. We have shown that under the uniform tariff regime the welfare level of the importing country is 
higher than under the discriminatory tariff regime. However, after the exporting countries have optimally chosen their export subsidies the importing country has an incentive to deviate to the discriminatory regime. These results holds for both Cournot and Bertrand competition between the exporting countries, and extend to differentiated goods and countries differing in the production costs. Hence, the MFN principle is not sustainable unless it is enforced by some outside body. This gives motivation for the existence of international agencies with the role of monitoring and enforcing tariff agreements.

\section{References}

Brander, J. A. (1995) "Strategic trade policy", in G. Grossman and K. Rogoff (eds.), Handbook of International Economics, Volume 3, 1395 - 1455, (Amsterdam: North-Holland).

Brander, J. and Spencer, B.J. (1984) "Tariff protection and imperfect competition", in H. Kierzkowski (ed.), Monopolistic Competition and International Trade (Oxford: Clarendon Press).

Brander J. A. and Spencer, B.J. (1985) "Export subsidies and international market share rivalry", Journal of International Economics, 18, 83 - 100.

Collie, D. R. and de Meza, D. (1986) "Inadequacies of the strategic rationale of export subsidies", Economics Letters, 22, 369 - 373.

Collie, D. R. and de Meza, D. (2003) "Comparative advantage and the pursuit of strategic trade policy", Economics Letters, 81, 279 - 283.

De Meza, D. (1986) "Export subsidies and high productivity: cause or effect", Canadian Journal of Economics, 19, 347 - 350.

Gatsios, K. (1990) "Preferential tariffs and the 'most favoured nation' principle: a note", Journal of International Economics, 28, 365 - 373.

Hoekman, B. M. and Kostecki, M.M. (2001) The Political Economy of the World Trading System (Oxford: Oxford University Press).

Horn, H., and Mavroidis, P.C. (2001) "Economic and legal aspects of the mostfavored nation clause", European Journal of Political Economy, 17, 233 279.

Hwang H. and Mai, C.C. (1991) "Optimum discriminatory tariffs under oligopolistic competition", Canadian Journal of Economics, 24, 693 - 702.

Liao, P. and Wong, K. (2006) "Uniform versus discriminatory tariffs: when will export taxes be used?", Southern Economic Journal, 72, 915 - 925.

Neary, J.P. (1994) "Cost asymmetries in international subsidy games: should governments help winners or losers?" Journal of International Economics, 37, $197-218$. 
Tirole, J. (1990) The Theory of Industrial Organization (Cambridge: MIT Press). 